\title{
Benchmarking of University teachers' professional development: successful European, Chinese, and Russian practices
}

\author{
Tatiana Tregubova \\ Institute of Pedagogy, Psychology and Social Problems, 420039, Isaeva St. 12, Kazan, Russia.
}

\begin{abstract}
In the context of socio-pedagogical transformations of higher education organizations, the modernization of the system of teachers' professional development becomes an integral component of the reforms. Today university teachers have to be ready for continuous development and advanced training throughout their lives. Thus, the study of the problem of university teachers' professional development in Russia and abroad is very relevant and timely as a response to the modern requirements of civil society for the personality of the teacher. The need for professional development among university teachers is closely related to his (her) desire for more successful indicators in teaching activities. To do this, it is necessary to fulfill several pedagogical conditions, including the teacher's own awareness of the need for professional development; the interest of the university administration and the availability of resources to organize an effective professional development system, etc. The purpose of the article is to show some successful practices of the teachers' professional development in Russian, Chinese and European universities which the author observed while visiting those universities within the realization the project "Enhancing teaching practice in the universities of Russia and China". The article presents the possibilities of benchmarking in higher education, in particular, the use of the benchmarking technology as a method of studying the effective practices of organizing the teachers' professional development in a modern university.
\end{abstract}

\section{Introduction}

The processes of globalization and international educational integration, the substantive characteristics of which include the intensification of international cooperation among universities, their effective interaction and interdependence, the virtualization of many areas of university activities and new types of interaction of regional and global practices, actualize the need of universities to maintain their competitive position in the educational services market through the use of new tools to ensure the quality of higher education, the availability of multiple formats for obtaining competences and introduction of dynamic interdisciplinary educational programs in accordance with the requirements of the global labor market $[1,2,3]$. All these factors have essentially increased the requirement to the higher education system and the challenges to teaching personnel, to their readiness for 
constant professional development within implementation of the Concept of Life Long Learning (LLL) in the Russian higher education.

Experiencing the influence of modern trends in the development of higher education, the system of teachers' professional development has become both their active participant, a catalyst, and a driving force. This causes the need to rethink the substantive characteristics and technologies for improving professional skills and professional retraining of university teaching staff. "New" professional roles (a teacher-tutor, an educator-facilitator, a teacher-researcher) require the reforming of the system of teachers' professional development, which should meet modern global and regional challenges, the state and public initiatives set before pedagogical education by the Russian National Project "Education" and all documents adopted in its development, and should be based on fundamentally new substantive and technological approaches.

Since the process of teachers' professional development continues throughout his professional activity, this process is very important in the framework of formal, informal or additional training. "The implementation of the cognitive paradigm of higher education assumes that innovative models of teachers' professional development should be designed, on the one hand, taking into account the social order of the system of advanced training, on the other hand, provide for the formation of mechanisms for intra-personal motivation of teachers on: professional growth, creating a situation of success not only among students, but also among teachers themselves, on the development of hard- and soft- competencies, improving the quality and efficiency of pedagogical work "[4, p. 89]. However, the analysis of special literature on this problem shows that the traditional models of the advanced training system used in Russian universities are often template stable and resource-cost due to inefficient investments in the systems of professional development of higher education teachers $[5,6,7]$. Implementation of the European experience of organizing a system of teachers' professional development can serve as a resource and guideline for increasing the effectiveness of reforming the domestic system, successfully transforming the best foreign practices and innovative useful information.

To conduct various comparative studies in the field of higher education, today there are many platforms, ratings and comparison technologies that allow us to identify the adaptively educational potential of a successful pedagogical phenomenon and the possibility of its implementation in the domestic education system. Here, Benchmarking Technology may be widely used as a tool for analyzing successful practices, identifying the best experience based on its comparison with similar organizations to increase (strengthen) the competitiveness of their own organization [8-11].

Benchmarking is a fairly popular technology used by European universities and credit agencies in order to control the quality, to improve organizational indicators of education and reengineering of business processes. However, the systematic use of benchmarking as an independent tool for assessing the effectiveness of the teachers' professional development in Russian universities is fragmented and small. And if earlier this was due, first of all, to the empirical ignorance of that problem, now this is due to the lack of conceptual research. In other words, there is a certain delay in the theoretical understanding of the effectiveness of using this technology in improving the system of professional development of university teachers in the partner countries of Russia within Bologna process, while studying the experience of solving educational problems in other countries allows Russian educators to make a more meaningful and adequate idea of the domestic system. This fact also demonstrates the relevance and timeliness of the issue discussed in this article. Therefore, it is necessary to overcome the old biases and new stereotypes associated with ignoring, or not carefully studying, from a certain professional angle, the real successes and problems of European colleagues in the field of improving the system of 
teachers' professional development and the use of modern technologies for comparative research in higher education.

\section{Methodology and methods for the research on benchmarking of teachers' professional development}

This study was aimed at identifying, using benchmarking technology, the most successful practices and finding a certain "standard" - "best of the best" in the field of professional development of teachers, to identify and analyze certain methods and strategies in achieving this standard.

A review of scientific literature and pedagogical sources on this issue included an analysis of available reliable sources of information on the problem, a number of articles and publications published in Russia and abroad. On the basis of the comparative pedagogical method, more than 30 definitions of the phenomena "benchmarking" and "benchmarking project" were identified, highlighting one or another facet of this technology. Such diversification suggests that there is no one-size-fits-all approach to determining the content and structure of benchmarking as an educational phenomenon, as it is a complex system of interrelated elements. There are differences in the interpretation of its components, in the types of benchmarking, in the directions of its use (more than 25), in the step-by-step implementation of this technology, in the choice of priorities and criteria when organizing comparative research, and, therefore, in the level of professional excellence of its implementation in the activities of the university administration or special agencies.

One of the most cited sources on this topic is the 1999 work of R. M. Epper entitled "Applying benchmarking to higher education: Some lessons from experience". This text defines benchmarking as a way of self-assessment and learning from the experience of others in order to improve their own activities, provides a detailed description of the types of reference analysis and the possibilities for its application in the higher education system. According to the author, benchmarking acts as a "trigger" ("trigger") more for internal analysis and assessment of the quality of higher education than as an external audit of the compliance of activities with standards and requirements [10].

D.V. Alstete argues that benchmarking helps overcome resistance to changes within the university/ He recommends an algorithm for external assessment of the university's activities, and also emphasizes the importance of creating new networks and connections between universities for the exchange of valuable information and practice [11]. According to C. Garlik and G. Pryor, the regular application of the benchmarking method allows us to have timely information about competitors and trends in the development of the educational sphere in their country, as well as in a concrete educational space [12].

Getting acquainted with various interpretations of benchmarking [13; 14] and an analysis of problems in its application in European universities, the characteristics (structure, components, requirements, definitions) of the components of this technology in the ideas of foreign researchers, which sometimes looked side-by-side or for granted, but they are by no means spelled out in the domestic pedagogical literature.

Based on the phenomenological approach, the essence and description of externally observed, variable characteristics of the use of benchmarking technology in assessing the activities of foreign universities were analyzed, and many paradigm and ideological "layers" were recorded, which indicates dominance at different stages of apologetics of socio-political or institutional points of view [15-17].

Despite this diversity in benchmarking definitions, all definitions include three main elements (steps) in benchmarking analyses, which are performed in the following order: 1 - 
finding and identifying successful best practices (experiences); 2 - systematic training from others; 3 - changes in the functioning of the university.

The Russian scientific community is also discussing the definition of the "benchmarking" phenomenon and the allocation of activities for the use of benchmarking technology, which is characterized as a useful, effective and understood means of remaining competitive in the international market of educational services $[18,19]$. Presenting the definitions of various scientists and combining the rational essence of the investigated variants, the article gives an author's understanding of this term.

\section{Analysis and Results}

In recent years, interest in the use of educational benchmarking has increased significantly, which is largely determined by the integration processes that are taking place in higher education in Russia, in China, and in the countries of the European Commonwealth. Educational benchmarking is evaluated as a response to the strategy of the Bologna Process countries to develop international cooperation and partnership in ensuring the quality of higher education in order to use the comparable methodologies and criteria in conditions of increasing competition among universities and the need to identify "best practices" to stimulate the exchange of relevant information on improving their educational activities.

Benchmarking accompanies almost all integration processes in various areas of higher education and its structures. With the growing popularity of educational benchmarking, the number of its definitions has increased, and such diversification is explained by the wide variety of subjects, and goals of benchmarking projects. "Key benchmarking ideas are: identifying best practices; obtaining the necessary information through appropriate selfassessment methods; work on self-improvement through the implementation of changes aimed at achieving and exceeding the established norms" [18, s.29]. By using benchmarking, it is possible "with its help to raise the questions about specific examples of successful introduction of innovations, as well as to analyze characteristics why these examples are successful and effective" [4, s.96].

The author's definition of educational benchmarking consists in understanding it as "an innovative technology for competitive analysis, measuring and comparing the results of the activities of leading educational organizations in order to search for the best pedagogical practices and effective models of education with their subsequent successful adaptation to develop development strategies, to increase competitiveness, and to increase the investment attractiveness of the educational organization at the educational services market" [4, s. 93]. The objects of the benchmarking project here can be the organization of systems for advanced training and retraining of teachers, internationalization of teacher professional development programs, models of professional development and teacher satisfaction with teaching activities, etc. Benchmarking answers the question "Why are they the best?" Benchmarking allows to determine the strengths and weaknesses of other universities participants in benchmarking projects, and then choose "number one" strategy for promoting their educational "product" or educational service.

The typology of educational benchmarking is also diverse, in which the most authors distinguish between associative, functional, competitive, general, and other types of benchmarking, which can be used both independently and comprehensively or in various combinations. Educational benchmarking in practice is implemented in the form of a "benchmarking project" according to a certain algorithm in several interconnected steps, the number of which is determined by the organizers of benchmarking, and it depends on the field of application and the desired level of detail.

The participation of the Institute of Pedagogy, Psychology and Social Problems (IPPSP) in international educational projects within the framework of the ERASMUS + programme 
stimulated the creation of the Center for International Cooperation and Academic Mobility at the Institute to increase the effectiveness and quality of scientific and methodological recommendations and developments, their demand by the international pedagogical community, and also provided a "platform" for the implementation of innovative educational "products.

As we have already pointed out, the problems of assessing the activities of the university and improving the system of teachers' professional development are very acute, and international project activity due to its integrative character and multiplicity of effects (the so-called phenomenon of "spin-off effect") makes a significant contribution for solving these problems through the development of joint scientific research and their demand in the service export market through academic exchanges and the development of the university's collaborative potential.

As an example, we will present some of the results of the Russian-Chinese-European project "Benchmarking of successful models of university teachers' professional development" which started at IPPSP in 2019 within the ENTEP project. This project is aimed at identifying successful practices of professional development of university teachers in order to find the best experience and develop recommendations for its use in Russian universities.

Following the step-by-step implementation of benchmarking technology, at the first stage, the process of professional development of university teachers was determined for comparative analysis, conceptualization and possible adaptation of the best practices of professional development of university teachers identified using this technology.

At the second stage, potential benchmarking project partners were identified; whose readiness to provide the necessary information and cooperation determined the type of benchmarking project and the success of comparative methods. European and Chinese universities were selected because they are IPPSP partners in the international consortia of the ERASMUS + Programme, and the IPPSP staff was able to visit those university within the ENTEP project life. Among them are the University of Bologna (Bologna, Italy), Dresden Technical University, the University of Coimbra (Portugal), University of Hildesheim (Hildesheim, Germany), Sanya University (Hainan, China) and Private Hualian University (Guangzhou, China). The framework and topics of the benchmarking project were defined, visits to partner universities took place, questionnaire forms and interviews for comparative research were prepared.

Numerous talks to the teaching staff of these universities as well as analysis of materials, provided by universities sites, and also the special observation during the visits have proved the importance and the necessity of the constant professional development of teachers for the enhancing the teaching practice and the competitiveness of the university on the whole.

At the third stage, which is currently ongoing, a comparative pedagogical analysis of data obtained through questionnaires, interviews, expert assessments and presentations of cases of European universities - carriers of successful practices of professional development of teachers is being carried out, as well as results that are of some interest to Russian higher schools are highlighted. So, it should be noted that in connection with the new increased requirements for the professional and personal qualities of teachers, to which challenges have also been added in connection with the COVID-19 pandemic, a total on-line system of "re-education of educators" has actually developed in European and Chinese universities, which is carried out by the Centers for Pedagogical Excellence, Centers for Technical Support of Education, Centers for Advanced Training and Professional Development, etc. The educational programs of these centers include courses such as "Skillful and Reflexive Teacher"; "Formation of a full professional"; "Teacher is an active leader in a multicultural society", etc. 
A comparative study of the content and principles of program design in teachers' training centers at the universities made it possible to distinguish three main models which individualize the process of professional development of teachers, which at this stage are called as professional-pedagogical, socio-pedagogical and personality-pedagogical models. These three main models implement plans for the individual development of teachers with a predominant focus on the professional, social and personal dimension of the professionalism of a university teacher.

Pilot testing of the effectiveness of these models, their adaptation and implementation on "domestic soil", accompanied by the searches for conditions of transfer and implementation, capable of maintaining the utility and efficiency in the Russian higher schools, will be carried out at the final, fourth stage of the benchmarking project.

\section{Conclusion}

Currently, in some Russian universities, a fragmented experience of individualizing the professional development of teachers has spontaneously formed, the importance and significance of which in the conditions of transformation and integration of higher education is beyond doubt. In this regard, an appeal to the international experience of organizing this process can serve as a guide and resource to solve this problem in the Russian higher schools.

Undoubtedly, successful practices of professional development of teachers abroad can be applied in Russian universities under certain conditions, in particular, it is necessary to intensify partnership and socio-professional contacts of universities in order to disseminate innovative experience and initiatives; Improve the culture and traditions of self-evaluation of universities; To prepare teachers to use successful international educational practices adapted to Russian reality, etc.

At the same time, we emphasize that in the conditions of international educational integration, Russian university teachers today have great opportunities for free communication with educators from other countries, and within the framework of international project activities, they should more actively promote traditionally Russian authentic models and formats of professional development of university teachers.

\section{References}

1. I.N. Ainoutdinova, T.M. Tregubova, A.N. Khuziakhmetov, MJLTM, 7, 9/2. 431 (2017)

2. C. Evans, M.J. Harkins, D. J. North Am. J. of Psych., 10. 567 (2008)

3. G. B. Kleiner. University as an Ecosystem: Institutes of Interdisciplinary Management. Journal of Institutional Studies. 11 (2019)

4. R. Kh. Gilmeeva, A. R. Kamaleeva, A. S. Katz, E. Y. Levina, and all. Cognitive pedagogy: teaching aid, 228 (2020)

5. P. Luksha. Educational ecosystems for the development of society. Education 20. 35. Man. ASI (2017)

6. M. Kagan Philosophy of culture, Yu-rait, Moscow (2019)

7. Y.I Kuzminov, D.N. Peskov D.N. Discussion. Education issues. - Moscow, HSE, 3. 202 (2017)

8. M. Porter. Alpika Publisher LLC. 716 (2018)

9. Benchmarking in Higher Education . Society for Research into Higher Education \& Open University Press. 258 (2006)

10. R.M. Epper, R.M. Applying benchmarking to higher education: Some lessons from experience. Change, 31(6). 24 (1999) 
11. L.W.Alstete. Business Officer. 238 (2006)

12. S.Garlick, G.Pryor. Benchmarking the university: Learning about improvement. A Report for the Department of Education, Science and Training. Regional Knowledge Works. 98 (2006)

13. R.Maloy. Contemporary Issues in Technology and Teacher Education, 16(2). 172 (2016)

14. E. Ossiannilsson. Society for Research into Higher Education \& Open University Press. 258 (2006)

15. N.P. Stromquist. Publisher: Education International. 120 (2018)

16. M. Warschauer, Learning Inquiry, 1, 1, 41 (2007)

17. B. Eickelmann, M. Vennemann, EERJ, 16, 6. 733 (2017)

18.N.Y.Mishchenko . Pedagogical science and practice. 1 (18). 28 (2018)

19. O.N. Ponomareva. XXXVII International Scientific and Practical Conference "World

Science: problems and innovations, Science and Education. 176 (2019) 